\title{
Reading Inflation Expectations from CPI Futures
}

\author{
Hui Guo and Kevin L. Kliesen
}

S tatements issued by the Federal Open Market Committee (FOMC) at the conclusion of each meeting suggest that inflation expectations matter a great deal to monetary policymakers. Therefore, if expected inflation moves above or below a level that is viewed as optimal, then the FOMC will presumably take action to counter those expectations. Although there are several measures of inflation expectations, a relatively new and potentially useful measure is one based on futures contracts written on the consumer price index (CPI); these have been traded on the Chicago Mercantile Exchange since February 9, 2004.

The contracts are based on the CPI for all urban consumers, all items (not seasonally adjusted). Similar to federal funds futures contracts, they have a pricing structure of 100 minus the contracted inflation rate-the three-month change in the CPI ending in the month prior to the expiration of the contract. According to the Chicago Mercantile Exchange, CPI futures can also be used as a derivative product to hedge inflation risk on other types of financial instruments, particularly Treasury inflation-protected securities (TIPS). ${ }^{1}$

The prices of CPI futures capture market participants' expectation of future inflation and the associated risk premium. For simplicity, we assume that the latter is negligible. Therefore, 100 minus the contract's price is approximately equal to the (annualized) expected inflation rate over the contracted period. If investors believe that the realized inflation rate will be lower than implied by the futures price, they will buy CPI futures and thus drive up the price until a new consensus is reached.

In the accompanying chart, the solid line plots the average inflation rate implied by the CPI futures. The average inflation rate, which partially smoothes through the seasonal pattern of the future three-month inflation rates (recall that the contracts are written on non-seasonally adjusted data), is simply the average of the outstanding contracts at any point in time. For example, the December 2005 inflation rate is the average of the yields on the March, June, September, and December 2005 contracts; the point plotted for March
2006 is the average of the March 2005 through March 2006 contracts, and so forth. Since CPI futures contracts are written on the same inflation series used for the TIPS, the average inflation rates are analogous to the rates of inflation compensation derived from yield spreads between nominal and inflation-indexed Treasury securities, with some minor adjustments.

One potential use of the CPI futures contracts, therefore, is to gauge the future inflation rate relative to the current rate. In 2004, the CPI rose 3.3 percent, the biggest increase in four years. Although a large part of the CPI increase was attributable to the jump in energy prices, it still raises the concern of whether inflation might be headed higher in the near future. However, a reading from the CPI futures market suggests that the inflation rate will moderate this year, perhaps because of an expected decline in energy prices, and then increase slightly in 2006 and 2007.

Despite its attractiveness to policymakers, the inflation outlook implied by CPI futures prices should be viewed cautiously because CPI futures contracts are relatively illiquid and have sizable bid-ask spreads. Nevertheless, when combined with a longer-run inflation compensation derived from the TIPS (dashed line), it appears that market participants believe that the FOMC-if necessary-will take the appropriate actions needed to keep inflation contained.

\footnotetext{
${ }^{1}$ For an overview of the CPI futures market, see www.cme.com/trading/prd/overview_CU5638.html.
}

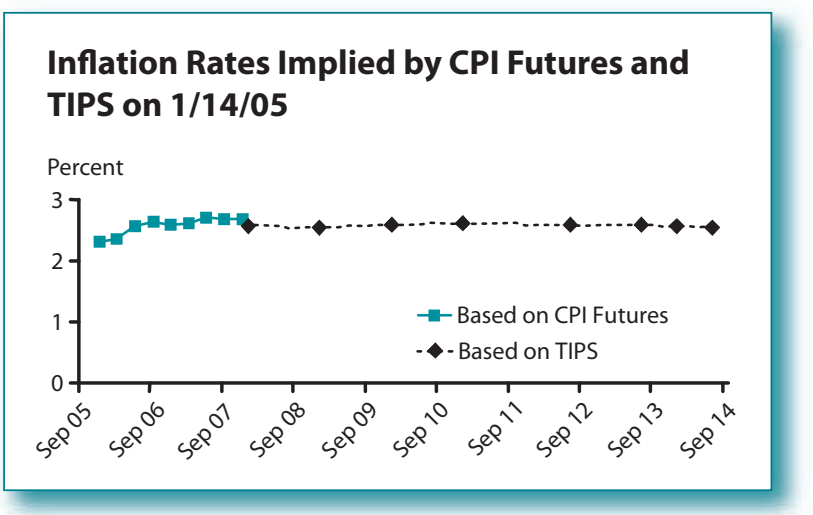

